\title{
ACCEPTABILITY AND WILLINGNESS TO PAY FOR INFLUENZA VACCINATION AMONG HEALTHCARE PROFESSIONALS IN VIETNAM
}

\section{Trang Thi Thu Nguyen', Vijj Kasemsup2*, Sariyamon Tiraphat', Samrit Srithamrongsawat2, Nalinee Nakittipha Chuakhamfoo' \\ 1. ASEAN Institute for Health Development, Mahidol University, Nakhon Pathom, Thailand \\ 2. Department of community medicine, Faculty of Medicine, Ramathibodi hospital, Mahidol University}

Correspondence:vij..kas@mahidol.ac.th

\begin{abstract}
\section{BACKGROUND:}

While Vietnam's Expanded Program on Immunization does not cover influenza vaccines, people must pay out-of-pocket for influenza vaccination. Healthcare professionals have a high risk of contracting influenza, but their vaccination rate is low.
\end{abstract}

\section{OBJECTIVE:}

To examine the willingness to pay (WTP) for influenza vaccination among healthcare professionals in Vietnam. It also recommends financing sources for influenza vaccination among healthcare professionals and determines possible measures to expand vaccine coverage.

\section{METHOD:}

We interviewed 130 healthcare professionals in a national hospital in Hanoi in July 2021 . We used Andersen's behavioral Model (ABM) as an initial approach. The double-bounded dichotomous-choice questions were used to determine WTP for influenza vaccination among the target group. Collected responses were coded and analysed through IBM SPSS version 20 for descriptive, chi-square analyses.

\section{RESULTS:}

Most of the healthcare professionals who responded to this study were female with $75.4 \%$ of the total 130 respondents. The mean age of participants was 34.08 years old. The average maximum WTP for influenza vaccination services was 357.57 VND (USD 15.3). Most of the participants reported that individuals should pay a part of the cost, and four-fifths reported they believed that the government and medical insurance should subsidize the service (80.8\% and $85.4 \%$ ). The Chi-square test showed that there was a significant association between perceived severity and history of influenza vaccination with the WTP, $X^{2}(1, N=130)=4.18, p=0.04, X^{2}(1, N=130)=7.81, p=0.005$, respectively.

\section{CONCLUSION:}

The WTP for influenza vaccination among healthcare professionals was found relatively high. Suggesting that price is not a primary barrier. The government and medical insurance were believed to be the potential agencies for improving 
vaccination uptake as these agencies were expected to be the subsidized actors. Other health interventions such as influenza literacy and communication methods are also needed to expand vaccine coverage.

\section{KEYWORDS}

influenza, influenza vaccination, Andersen's behavioral model, willingness-to-pay, healthcare professionals

The paper was presented at The Hong Kong Polyłechnic University's College of Professional and Continuing Education (CPCE) Conference "Post-pandemic health and long-term care: A new paradigm". September 2021

\section{INTRODUCTION}

Influenza (flu) is a disease caused by the influenza virus. When infected with the influenza virus, people will develop fever, cough, sore throat, headache, muscle pain, sheer tiredness, and runny nose. [1] It transmits through droplets from ill people when they cough, sneeze, or talk, so the flu quickly spreads. Most people who get flu will recover within a few days to less than two weeks, but some will develop complications like sinus and ear infection, inflammation of the heart and brain. [1]

Influenza virus infections are one of morbidity and mortality burden worldwide. According to the World Health Organization, influenza epidemics cause about 3-5 million severe illness cases and about 290,000 to 650,000 respiratory deaths each year. [2] People of all age groups can infect with the influenza virus. However, some groups have a higher risk for developing severe complications when getting flu, such as children under five years old, adults 65 years and older, adults with chronic health conditions, pregnant women, and health care workers. [2] The highest mortality rates of flu were estimated in subSaharan Africa (2.8-16.5 per 100000 individuals), south-east Asia (3.5-9.2 per 100,000 individuals) [3]. One national survey in Vietnam showed that $22 \%$ of patients presenting with ILI were influenza-positive. [4] Among them, 9,3\% reported as hospitalized, of which $19 \%$ were influenza positive. [4]

The influenza vaccine is the most effective way of reducing the morbidity and mortality of flu. Vaccination is vital for high-risk groups that are easy to develop severe complications from influenza. Healthcare professionals are responsible for providing health care treatment and advice for patients. It means that they contact directly with their patients and be put in a high-risk environment for getting the influenza virus. However, this population's acceptance and vaccine uptake rate is still low. [5-8]
Some studies have examined factors affecting the acceptability and willingness-to-pay (WTP) for influenza vaccine in several subjects, including the woman of childbearing age in Vietnam. [9] the general population in China. [10] However, little is known about the acceptance of WTP for influenza vaccine among healthcare professionals. In 2011 , the Ministry of Health (MOH) Vietnam legislated seasonal diagnosis and treatment guidelines. HCWs were identified as one of high risk of infection and recommended to be vaccinated annually. [11] However, Vietnam's expanded program on immunization (EPI) does not cover the influenza vaccine. Moreover, social health insurance also does not include vaccination services in the benefit packages. To vaccinate against flu, Vietnamese people pay USD 5,2-7,8 for local vaccines [12] and around USD 1 1,9-14,4 for the imported vaccine. [13] On the other hand, the average cost of ILI treatment in Vietnam was USD 88.09 per case for all age groups. [14] We can see that vaccination programs could help reduce the economic burden of influenza illness. However, there is no studies that examined healthcare professionals' WTP for influenza vaccination in Vietnam.

Andersen's behavioural model of health services use (ABM) $[15,16]$ is applied in various studies on health service utilization. This model provides a framework for describing and understanding individuals' decisions to use health care services, including vaccination. [17] The dependent variable in this study, the willingness-to-pay for influenza vaccination, is considered a health care utilization, like other studies. $[18,19]$ The independent variables included three factors: predisposing, enable, and need factors. Predisposing factors include sociodemographic characteristics like age, gender, occupation, and education. Enabling factors refer to resources for accessing health services (such as health insurance, availability of service, etc.). Need factors are about people's perceived needs to access healthcare services. 
Therefore, we conducted this research to determine the acceptability and WTP for influenza vaccination and factors associated with the willingness to pay for influenza vaccination among health care professionals. It also recommends financing sources for influenza vaccination among healthcare professionals and determines feasible measures to expand vaccine coverage.

\section{METHODOLOGY}

\section{STUDY DESIGN AND AREA}

We conducted a rapid assessment among healthcare professionals at the National Hospital for Tropical Diseases in Vietnam in July 2021. This hospital focuses on infectious disease treatment, such as influenza, COVID-19. Therefore, it is essential to maintain their health through an influenza vaccination program. So, understanding healthcare professionals' acceptability and willingness to pay for this vaccine to increase the vaccine uptake could be beneficial for social health protection in Vietnam.

\section{TARGET POPULATION}

The healthcare professionals currently working in the hospital, over 18 years old, cognitively healthy, were eligible for this study, and the exclusion criteria were refusing to participate. The healthcare professionals in this study were doctors, nurses, technicians, and pharmacists.

\section{MEASURES AND INSTRUMENT}

We developed a structured questionnaire as an instrument in this study. First, the questionnaire was written in English; then, it was revised and translated into Vietnamese by a language expert.

The final version of the questionnaire was divided into five sections:

1. The first sections included questions about sociodemographic information of participants such as age, gender, living area, education level, occupation, maternal status, and general knowledge about the influenza vaccine.

2. The second section asked participants about enabling factors such as their monthly income, awareness about influenza vaccination, and the sources of information and encouraging factors they received.

3. The third section was about needs factors, which included participants' self-ranking health status, perceived needs, the experience of influenza vaccination, and the reason for getting or not getting the influenza vaccine.

4. The fourth section asked about the acceptance and WTP for influenza vaccination. We used double-bounded dichotomous-choice questions to ask how much the participants would pay for one flu shot. The initial price in our study was 200,000 VND ( USD 8,6, 2021 exchange rate from The State bank of Vietnam) which was adapted from another study in Vietnam [9]. The researcher asked the participant whether they were willing to pay 200,000 VND for one dose of influenza vaccine. Then, the double bid and half bids were then asked following the "yes" and "no" responses, respectively. Lastly, the participants will be asked an open-ended question about the maximum price they can pay for influenza vaccination.

5. The fifth section is about participants' thoughts on the responsibility of individuals, medical insurance, and government in terms of paying for influenza vaccination. They also answered about their expectations in financial support from the medical insurance and government.

\section{PROCEDURES}

Before data collection, the researcher asked permission to collect data from the National Hospital for Tropical disease. Then, the researcher went to the hospital and interviewed the eligible participants based on inclusion and exclusion criteria. The participants were randomly selected based on the list of healthcare professionals in this hospital.

\section{STATISTICAL ANALYSIS}

The data were coded and analyzed using IBM Statistical Packages for the Social Sciences (version 20).

Descriptive statistics were calculated to understand the participants' sociodemographic characteristics and the percentage of influenza vaccine uptake and WTP.

Chi-square test of independence was performed in our study to find factors affecting the WTP for influenza vaccination.

\section{ETHICAL APPROVAL}

The Institutional Review Board, Institute for Population and Social Research, Mahidol University approved the research protocol, with a certificate of approval number2021/06-136 in July 2021 . The researcher explained the objectives of the study with potential risks and benefits for the participants. All the participants of the respondents were also identified as confidential. Participants were interviewed at the hospital in a private area after giving written consent. 
RESULTS

\section{GENERAL CHARACTERISTICS OF PARTICIPANTS}

The total response rate in this study was $76,5 \%$ because there were 130 respondents out of 170 healthcare professionals who were interviewed. Therefore, the final sample size used for analysis was 130. The sociodemographic characteristics of participants were shown in Table 1. More than three-quarters of the participants were female. The participants' age ranged from 22 to 63 with a mean age of 34.8 years old $(S D=7.76)$. There were two- third of the participants live in an urban area. The participants who had university degrees accounted for $46.9 \%$, followed by the college with $30.8 \%$. The largest part of participants was nurses, which was $42.3 \%$.

The dominant part of participants were married (76.9\%) and $59.2 \%$ of families had four to five members. Most of the participants knew the priority group for influenza vaccination (90\%), while $43.8 \%$ of them knew vaccine price. The family which had an income from 15 to 20 million VND accounted for $65.4 \%$.

TABLE 1. SOCIODEMOGRAPHIC CHARACTERISTICS OF PARTICIPANTS $(\mathrm{N}=130)$

\begin{tabular}{|c|c|c|}
\hline Baseline Characteristics & $n$ & $\%$ \\
\hline \multicolumn{3}{|l|}{ Age group } \\
\hline From 21 to 30 years old & 49 & 37.7 \\
\hline From 31 to 40 years old & 62 & 47.7 \\
\hline Over 41 years & 19 & 14.6 \\
\hline \multicolumn{3}{|c|}{ Mean $=34.8, S D=7.76, \operatorname{Min}=22, \operatorname{Max}=63$} \\
\hline \multicolumn{3}{|l|}{ Gender } \\
\hline Male & 32 & 24.6 \\
\hline Female & 98 & 75.4 \\
\hline \multicolumn{3}{|l|}{ Living area } \\
\hline Urban & 91 & 70 \\
\hline Rural & 39 & 30 \\
\hline \multicolumn{3}{|l|}{ Education } \\
\hline College & 40 & 30.8 \\
\hline University & 61 & 46.9 \\
\hline Postgraduate & 29 & 22.3 \\
\hline \multicolumn{3}{|l|}{ Occupation } \\
\hline Doctor & 45 & 34.6 \\
\hline Nurse & 55 & 42.3 \\
\hline Other (Technician, Pharmacist) & 30 & 23.1 \\
\hline \multicolumn{3}{|l|}{ Marital status } \\
\hline Married & 100 & 76.9 \\
\hline Other & 30 & 23.1 \\
\hline \multicolumn{3}{|l|}{ Family member } \\
\hline$\leq 3$ & 47 & 36.2 \\
\hline $4-5$ & 77 & 59.2 \\
\hline$\geq 6$ & 6 & 4.6 \\
\hline
\end{tabular}




\begin{tabular}{|c|c|c|}
\hline Baseline Characteristics & n & $\%$ \\
\hline \multicolumn{3}{|c|}{ Mean $=3.71, S D=1.023, \operatorname{Min}=1, \operatorname{Max}=8$} \\
\hline \multicolumn{3}{|l|}{ Knowing vaccine price } \\
\hline Yes & 57 & 43.8 \\
\hline No & 73 & 56.2 \\
\hline \multicolumn{3}{|c|}{ Know priority group of influenza vaccination } \\
\hline Yes & 117 & 90 \\
\hline No & 13 & 10 \\
\hline \multicolumn{3}{|c|}{ Monthly household income (VND) } \\
\hline$\leq 15.000 .000$ & 13 & 10.0 \\
\hline $15-20.000 .000$ & 85 & 65.4 \\
\hline$\geq 20.000 .000$ & 32 & 24.6 \\
\hline Mean $=20.57, S D=7.486,1$ & & \\
\hline
\end{tabular}

\section{ACCEPTANCE OF INFLUENZA VACCINATION AMONG HEALTHCARE PROFESSIONALS}

The participant's health status, perceived needs, influenza vaccine uptake, and the reasons for getting or not getting the influenza vaccine were presented in Table 2. The majority part of participants showed their acceptance of influenza vaccination (95.4\%) which mean that they will vaccinate against flu if the vaccine is free. The participants who perceived that they were susceptible to influenza virus and flu as a severe illness were $76.9 \%$ and $63.8 \%$, respectively. While $67.7 \%$ of them reported an influenzalike illness in the past, only $31.5 \%$ were vaccinated influenza vaccine in 2020 . The most common reason for getting an influenza vaccine was self-protection (35.7\%), and the most common reason for not getting an influenza vaccine was influenza is not severe

tABle 2. ACCEPTANCE, AWARENESS OF INFLUENZA VACCINATION AND tHE REASONS FOR GetTING OR NOt GetTING INFLUENZA VACCINE $(\mathrm{N}=130)$

n

$\begin{array}{lll} & \mathbf{n} & \% \\ \text { Self-ranking health status } & 18 & 13.8 \\ \text { Excellent } & 89 & 68.5 \\ \text { Good } & 23 & 17.7 \\ \text { Fair } & 0 & 0 \\ \text { Poor } & & \\ \text { Perceived susceptibility } & 100 & 76.9 \\ \text { Yes } & 30 & 23.1 \\ \text { No } & & \\ \text { Perceived Severity } & 83 & 63.8 \\ \text { Yes } & 47 & 36.2 \\ \text { No } & & 67.7 \\ \text { History of Influenza-like illness } & 88 & \\ \text { Yes } & & \end{array}$




\begin{tabular}{|c|c|c|}
\hline & n & $\%$ \\
\hline No & 42 & 32.3 \\
\hline \multicolumn{3}{|l|}{ History of Influenza vaccination } \\
\hline Yes & 41 & 31.5 \\
\hline No & 89 & 68.5 \\
\hline \multicolumn{3}{|l|}{ Acceptability of influenza vaccination } \\
\hline Yes & 124 & 95.4 \\
\hline No & 6 & 4.6 \\
\hline \multicolumn{3}{|l|}{ Reasons for vaccinating } \\
\hline Self protection & 40 & $35.7 \%$ \\
\hline Protect family/colleagues & 30 & $26.8 \%$ \\
\hline Protect patients & 13 & $11.6 \%$ \\
\hline Afraid of contracting the influenza virus & 18 & $16.1 \%$ \\
\hline Experienced influenza & 11 & $9.8 \%$ \\
\hline \multicolumn{3}{|l|}{$\begin{array}{l}\text { Reasons for not vaccinating } \\
\text { (multiple-choose items) }\end{array}$} \\
\hline Never get influenza & 18 & $13.7 \%$ \\
\hline Influenza is not serious & 34 & $26.0 \%$ \\
\hline Acquire immunity from work & 33 & $25.2 \%$ \\
\hline Natural infection provides better immunity & 6 & $4.6 \%$ \\
\hline Afraid of vaccine side effect & 5 & $3.8 \%$ \\
\hline The vaccine is not effective & 4 & $3.1 \%$ \\
\hline Lack of time & 18 & $13.7 \%$ \\
\hline Vaccine shortage & 1 & $0.8 \%$ \\
\hline Difficult to access & 0 & 0 \\
\hline Other & 12 & $9.2 \%$ \\
\hline
\end{tabular}

\section{WILLINGNESS-TO-PAY FOR INFLUENZA VACCINATION} Table 3 shows the participant's WTP for influenza vaccination. Among 130 participants, 116 (89.2\%) reported that they were willing to pay for the influenza vaccine. Over $80 \%$ of them were willing to pay for this vaccine at equal or higher than the initial price (200,000 VND). The mean and median of the maximum amount of WTP for influenza vaccination were 357.57VND (USD 15.3) and 275.000 (USD 11.8), respectively.

\section{RECOMMEND FINANCING SOURCES FOR INFLUENZA VACCINATION}

Almost all participants (92.3\%) thought that they should participate in paying for influenza vaccination. Otherwise, most of them also agreed that medical insurance $(85.4 \%)$ and government $(80.8 \%)$ are responsible for paying for influenza vaccination services. Over $90 \%$ of them want to receive financial support from medical insurance and the government. In which, there were $34.6 \%$ want to receive fully subsidized.

\section{FACTORS AFFECTING WTP FOR INFLUENZA VACCINATION}

There was no association between socio-demographic factors such as age, gender, education, occupation, and household monthly income with the WTP. The table showed that there was a significant association between perceived severity and history of influenza vaccination with the WTP, $X 2(1, N=130)=4.18, p=0.04$ and $X^{2}(1, N=130)=$ $7.81, p=0.005$, respectively. 
TABLE 3. THE WTP FOR INFLUENZA VACCINATION

\begin{tabular}{lcc} 
& $\mathbf{N}$ & $\%$ \\
\hline WTP & 116 & 89.2 \\
Yes & 14 & 10.8 \\
No & 130 & 100 \\
Total & & \\
Maximum amount of WTP (VND) & 20 & 17.24 \\
$<200.000$ & 68 & 58.62 \\
$200.000-400.000$ & 28 & 24.14 \\
$>400.000$ & 116 & \\
Total & 246.877, Min $=50.000$, Max $=1.000 .000$ \\
Mean $=357.57$, Median = 275.000,SD $=24$
\end{tabular}

TABLE 4. RECOMMEND FINANCING SOURCES FOR INFLUENZA VACCINATION $(\mathrm{N}=130)$

\begin{tabular}{lll} 
& $\mathbf{n}$ & $\%$ \\
\hline Responsibility of individuals & 120 & 92.3 \\
Responsibility of medical insurance & 111 & 85.4 \\
Responsibility of government & 105 & 80.8 \\
\hline Percentage of financial support & & \\
$100 \%$ & 45 & 34.6 \\
$75 \%$ & 19 & 14.6 \\
$50 \%$ & 49 & 37.7 \\
$25 \%$ & 6 & 4.6 \\
$0 \%$ & 11 & 8.5 \\
\hline
\end{tabular}

\section{TABLE 5. ASSOCIATION BETWEEN WTP WITH INDEPENDENT VARIABLES}

\begin{tabular}{|c|c|c|c|c|}
\hline & WTP & & & p-value \\
\hline & Yes & No & & \\
\hline & n $(\%)$ & n $(\%)$ & & \\
\hline Age group & & & 4.48 & .11 \\
\hline From 21 to 30 years old & $46(93.9)$ & $3(6.1)$ & & \\
\hline From 31 to 40 years old & $51(82.3)$ & $11(17.7)$ & & \\
\hline Over 41 years & $18(94.7)$ & $1(5.3)$ & & \\
\hline Gender & & & .70 & .41 \\
\hline Male & $27(84.4)$ & $5(15.6)$ & & \\
\hline Female & $88(89.8)$ & $10(10.2)$ & & \\
\hline Education & & & 3.14 & .21 \\
\hline College & $36(90)$ & $4(10)$ & & \\
\hline University & $56(91.8)$ & $5(8.2)$ & & \\
\hline Postgraduate & $23(79.3)$ & $6(20.7)$ & & \\
\hline Occupation & & & 1.10 & .34 \\
\hline
\end{tabular}




\begin{tabular}{|c|c|c|c|c|}
\hline & WTP & & Pearson & $p$-value \\
\hline & & & & \\
\hline Doctor & $40(88.9)$ & $5(11.1)$ & & \\
\hline Nurse & $50(90.9)$ & $5(9.1)$ & & \\
\hline Other (Technician, Pharmacist) & $25(83.3)$ & $5(16.7)$ & & \\
\hline Marital status & & & .91 & .52 \\
\hline Married & $87(87)$ & $13(13)$ & & \\
\hline Other & $28(93.3)$ & $2(6.7)$ & & \\
\hline Monthly household income (VND) & & & 2.22 & .33 \\
\hline$\leq 15.000 .000$ & $13(100)$ & 0 & & \\
\hline $15-20.000 .000$ & $75(88.2)$ & $10(11.8)$ & & \\
\hline$\geq 20.000 .000$ & $27(84.4)$ & $5(15.6)$ & & \\
\hline Perceived susceptibility & & & 1.01 & .32 \\
\hline Yes & $90(90)$ & $10(10)$ & & \\
\hline No & $25(83.3)$ & $5(16.7)$ & & \\
\hline Perceived Severity & & & 4.18 & $.04 *$ \\
\hline Yes & $77(92.8)$ & $6(7.2)$ & & \\
\hline No & $38(80.9)$ & $9(19.1)$ & & \\
\hline History of Influenza-like illness & & & $.01 *$ & .93 \\
\hline Yes & $78(88.6)$ & $10(11.4)$ & & \\
\hline No & $37(88.1)$ & $5(11.9)$ & & \\
\hline History of Influenza vaccination & & & 7.81 & $.005 *$ \\
\hline Yes & $41(100)$ & 0 & & \\
\hline No & 74 (83.1) & $15(16.9)$ & & \\
\hline
\end{tabular}

\section{DISCUSSION}

Our study highlighted the low uptake, high acceptability, and a high amount of WTP for influenza vaccination among healthcare professionals in Vietnam, showing that the price is not the gatekeeper to influenza vaccination. It is expected that we can expand the influenza vaccination program in these subjects. We also discovered that perceived severity and the history of influenza vaccination might influence the WTP for that vaccine.

Our findings show a low percentage of influenza vaccine uptake among healthcare professionals in Vietnam (31.5\%). This result was higher than other studies in Greece (28.7\%) [6] and Turkey (23.1\%) [7], but lower than that in the previous study in Vietnam (48\%) [5] and Spain (49.7\%) [8]. This finding can be explained by the differences in study population and policies related to vaccination programs among countries. Our study examined the influenza vaccine uptake among healthcare professionals who take care of patients directly, while other studies' populations are general healthcare workers. The flu vaccine is not mandatory in Vietnam and is not included in the Expanded Program on immunization, so people have to pay fully for the vaccine. Otherwise, in some countries like the United States, the flu vaccine is recommended for all individuals from 6 months [20].

In our study, $90 \%$ of participants knew the priority group for influenza vaccine price, and $43.8 \%$ knew vaccine price. These findings are much higher than the results in one study among women of childbearing age (rural. It might be because of the participant's awareness related to influenza illness and vaccination. Nevertheless, the findings in our study also indicated that the two common reasons for not getting the influenza vaccine was influenza is not severe $(26 \%)$ and acquiring immunity from work (25.2\%). Therefore, a campaign and communication program need to be done to reduce misunderstandings about influenza illness. 
The mean of WTP for one dose of influenza vaccine in this study was 357.57 VND (USD 15.3), higher than the current price of both local and imported influenza vaccines, suggesting that price is not a primary barrier. Therefore, it is feasible to expand the vaccine coverage in this population. Even though over $80 \%$ of healthcare professionals in this study were willing to pay for influenza with the price of 200,000 VND, the perception of subsidization from the government or health insurance also helps us understand why the uptake rate of the vaccine is low, $31.5 \%$. \%. As $86,9 \%$ of participants indicated that the government or health insurance should pay at least half of the vaccine's price and almost half of them need more subsidization up to $75 \%$ of the vaccine's price. Therefore, if the government wants to have a vaccination uptake rate of more than 60 percent among health care professionals in Vietnam, subsidization of at least $75 \%$ should be secured.

The findings from our study have several implications. More studies need to be conducted on the acceptability and WTP for influenza vaccination in Vietnam. Regular training and educational program should be implemented to raise healthcare professional's awareness and practices towards flu vaccination. To expand the flu vaccine coverage in healthcare professionals, the government should enforce new policies that subsidize them.

Although, our study has some limitations. Firstly, we collected data in only one hospital; therefore, the findings are a weak generalization. Secondly, the cross-sectional design makes it difficult to explain the causality between the independent variables and the WTP. However, we enhanced the study's validity by randomly selecting the participants and training the researchers' team to highquality data collection.

\section{CONCLUSION}

This study reveals low vaccine uptake, high acceptability, and a high amount of WTP for influenza vaccination among healthcare professionals in Vietnam. It suggests that price is not a primary barrier, and expanding the immunization program to healthcare professionals would be much appreciated. Four-fifths of participants expected the government and medical insurance subsidies, so financing support up to $75 \%$ of the vaccine's price from these sources could improve the vaccine uptake rate of a healthcare professional and public at large. In addition, the training and educational program inside or outside the hospital can raise healthcare professionals' awareness about flu and change their practices related to influenza vaccination.

\section{DECLARATION OF COMPETING OF INTEREST}

The authors declare that they have no known competing financial interests or personal relationships that could have appeared to influence the work reported in this paper.

\section{ACKNOWLEDGMENT}

The authors acknowledged a scholarship from the International Labour Organization through the ILO-LuX project for the regional facility on social health protection in the South-East Asia approach to Miss Trang Thi Thu Nguyen and ASEAN Institute for Health Development, Mahidol University via Master of Primary Healthcare Management special track on Social Health Protection Program.

\section{References}

1. Seasonal Influenza (Flu). Flu symptoms and complications.; Available from: https://www.cdc.gov/flu/symptoms/symptoms.htm .

2. Influenza (seasonal). 2018; Available from: https://www.who.int/news-room/factsheets/detail/influenza-(seasonal).

3. IUliano, A.D., et al., Estimates of global seasonal influenza-associated respiratory mortality: a modelling study. (1474-547X (Electronic)).

4. Nguyen, Y.T., et al., National surveillance for influenza and influenza-like illness in Vietnam, 2006-2010. Vaccine, 2013.31 (40): p. 4368-4374.

5. Nguyen, T.T.M., et al., Acceptability of seasonal influenza vaccines among health care workers in Vietnam in 2017. Vaccine, 2020. 38(8): p. 2045-2050.

6. Rachiotis, G., et al., Low acceptance of vaccination against the 2009 pandemic influenza $A(H 1 N 1)$ among healthcare workers in Greece. Eurosurveillance, 2010. 15(6): p. 19486

7. Baguelin, M., et al., Vaccination against pandemic influenza A/H1N 1 v in England: a real-time economic evaluation. Vaccine, 2010.28(12): p. 2370-2384.

8. Vírseda, S., et al., Seasonal and Pandemic A ( $\mathrm{H} 1 \mathrm{Nl})$ 2009 influenza vaccination coverage and attitudes among health-care workers in a Spanish University Hospital. Vaccine, 2010.28(30): p. 4751-4757. 
9. Le, X.T., et al., Rural-urban differences in preferences for influenza vaccination among women of childbearing age: implications for local vaccination service implementation in Vietnam. Tropical Medicine \& International Health, 2021.26(2): p. 228-236.

10. Lai, X., et al., Willingness to Pay for Seasonal Influenza Vaccination among Children, Chronic Disease Patients, and the Elderly in China: A National CrossSectional Survey. Vaccines, 2020.8(3).

11. Guidlines of seasonal influenza diagnose and treatment. 2011; Available from: https://thuvienphapluat.vn/van-ban/The-thao-Yte/Quyet-dinh-2078-QD-BYT-huong-dan-chan-doanva-dieu-tri-cum-mua-126333.aspx.

12. VietNam News - Society. Made-in-Vietnam seasonal influenza vaccines are available. 2019; Available from: https://vietnamnews.vn/society/483927/made-invietnam-seasonal-influenza-vaccines-areavailable.html\#yFPhxb20VXv0sZ6Y.97.

13. Vietnam Vaccine JSC. How much does it cost to get a flu shot? ; Available from: https://vnvc.vn/faq/tiemvac-xin-cum-het-bao-nhieu-tien/.

14. Quang Vo, T., et al., Social and economic burden of patients with influenza-like illness and clinically diagnosed flu treated at various health facilities in Vietnam. ClinicoEconomics and outcomes research: CEOR, 2017.9: p. 423-432.

15. Andersen, R., A behavioral model of families' use of health services. A behavioral model of families' use of health services., 1968(25).

16. Andersen, R.M., Revisiting the behavioral model and access to medical care: does it matter? Journal of health and social behavior, 1995: p. 1-10.

17. Lee, H.Y., et al., Male undergraduates' HPV vaccination behavior: implications for achieving HPVassociated cancer equity. Journal of community health, 2018.43(3): p. 459-466.

18. Al-Tawfiq, J.A., A. Antony, and M.S. Abed, Attitudes towards influenza vaccination of multi-nationality health-care workers in Saudi Arabia. Vaccine, 2009. 27(40): p. 5538-5541.

19. Liv, Z., et al., Factors Influencing Residents' Willingness to Contract With General Practitioners in Guangzhou, China, During the GP Policy Trial Phase: A CrossSectional Study Based on Andersen's Behavioral Model of Health Services Use. INQUIRY: The Journal of
Health Care Organization, Provision, and Financing, 2019.56: p. 0046958019845484.

20. Grohskopf,L.A., et al., Prevention and control of seasonal influenza with vaccines: recommendations of the Advisory Committee on Immunization Practices-United States, 2019-20 influenza season. MMWR Recommendations and reports, 2019. 68(3): p. 1. 